\title{
CURADORIA DIGITAL PARA GOVERNANÇA CORPORATIVA DE OBJETOS DIGITAIS XAVANTE E BORORO
}

\author{
Heloisa Costa ${ }^{1}$
}

Resumo: Os estudos sobre curadoria digital e sua aplicação estão cada vez mais presentes na gestão de unidades de informação, em especial na gestão dos objetos digitais. A curadoria pode ser vista como um processo essencial a ser inserido na gestão de unidades de informação (arquivos, museus, bibliotecas, centros de informação), pois visa criar espaços para armazenar e disponibilizar informações úteis à comunidade interna e externa de usuários a qual atende, visando a permanência desse armazenamento, acesso, uso e reuso. Este projeto está voltado para o entendimento do tratamento de objetos digitais de unidades de informação, especificamente em uma aplicação prática do modelo de curadoria digital para os objetos digitais de três Unidades de Informação da Missão Salesiana de Mato Grosso (museu, biblioteca e arquivo). Apresenta como objetivo geral: sistematizar e aplicar um modelo de curadoria digital integrado para o acervo de objetos digitais das unidades de informação da Missão Salesiana de Mato Grosso. Utiliza como procedimentos metodológicos a pesquisa bibliográfica e documental, exploratória e descritiva, com abordagem qualitativa e elementos de estudo de caso. Como resultado esperado, pretendese apresentar e implementar um modelo integrador dos objetos digitais das unidades de informação estudadas, apoiada na curadoria digital, permitindo disponibilizar as coleções/acervos virtualmente a toda a comunidade de usuários.

Palavras-Chave: Curadoria digital. Preservação e acesso. Unidades de Informação. Xavante. Bororo.

\section{INTRODUÇÃO}

A preservação e manutenção da informação digital por longos períodos é um tema bastante abordado em diferentes áreas do conhecimento, pois as atividades de preservação e consequente garantia de uso e reuso da informação durante o seu ciclo de vida é um desafio para os profissionais que atuam com a gestão de acervos.

A criação, gestão e uso de materiais digitais são cada vez mais importantes para uma ampla gama de atividades, considerando-se o desenvolvimento tecnológico e que a rede é o canal para disponibilização de informações de interesse social, diverso ou aplicado, que inclui a comunicação de resultados de pesquisa científica.

\footnotetext{
${ }^{1}$ Doutoranda do Programa de Pós-graduação em Ciência da Informação, do Departamento de Ciência da Informação da Universidade Federal de Santa Catarina, sob orientação do Professor Dr. William Barbosa Vianna - Linha de Pesquisa: Informação, Gestão e Tecnologia - Eixo: Gestão da informação e do conhecimento - E-mail: helocosta7@hotmail.com
} 
Autores como Gray (2007), Mayer-Schonbeerger e Cukier (2013) destacam a importância das tecnologias da informação e comunicação na forma de como se faz ciência, e que entre os desafios tecnológicos está a necessidade de melhor captação, análise, modelagem, visualização e preservação das informações científicas, o que faz com que os sistemas computacionais sejam vitais para a realização e disponibilização de pesquisas.

Para Ferreira (2006, p. 20),

a preservação digital consiste na capacidade de garantir que a informação digital permaneça acessível e com qualidades de autenticidade suficientes para que possa ser interpretada no futuro recorrendo a uma plataforma tecnológica diferente da utilizada no momento da sua criação. (FERREIRA, 2006, p. 20).

Contudo, a curadoria digital abarca um conceito mais amplo quando trata não somente das ações de preservação, mas da "avaliação e a gestão ativa dos dados digitais ao longo do seu ciclo de vida, em que se consideram os processos para a manutenção, preservação e agregação de valor aos dados”. (DIGITAL CURATION CENTRE, 2017). Nesse sentido, a curadoria pode ser vista como um processo essencial a ser inserido na gestão de unidades de informação (arquivos, museus, bibliotecas, centros de informação), pois visa criar espaços para armazenar e disponibilizar informações úteis à comunidade interna e externa de usuários a qual atende, visando a permanência desse armazenamento, acesso, uso e reuso.

Nessa perspectiva, este projeto está voltado para o tratamento de objetos digitais de unidades de informação, especificamente em uma aplicação prática do modelo de curadoria digital para os objetos digitais das Unidades de Informação da Missão Salesiana de Mato Grosso: Museu das Culturas Dom Bosco, Biblioteca Pe. Félix Zavattaro da Universidade Católica Dom Bosco (UCDB) e Arquivo de documentos das culturas Xavante e Bororo, cuja unidade conservadora desses documentos encontra-se na Aldeia de Sangradouro, no Mato Grosso. Atualmente, as unidades de informação Museu e Biblioteca contêm objetos digitais em plataformas e sistemas diferentes, adequados a cada UI.

Numa era em que a necessidade de acessar informações está acelerada por conta do desenvolvimento tecnológico, pretende-se investigar como essas unidades de informação estão trabalhando com a disponibilização de acervos digitais e com a gestão ativa de dados digitais, voltadas, sobretudo, à preservação para acesso 
futuro às suas coleções/acervos. Além disso, entende-se ser importante a tomada de consciência dos profissionais que atuam em unidades de informação sobre os problemas referentes à preservação de documentos em meio digital, sobretudo no que diz respeito à disponibilização da informação digital aos usuários.

Neste projeto trabalha-se com a concepção de que a curadoria digital pode ser um processo de estabelecimento e manutenção de um corpo confiável de informação digital, que cuida da preservação em longo prazo para uso corrente e futuro por pesquisadores, historiadores e acadêmicos, incluindo o acesso da comunidade de usuários a qual determinado acervo atende. Dessa forma, o objetivo geral consiste em: Sistematizar e aplicar um modelo de curadoria digital integrado para o acervo de objetos digitais das unidades de informação da Missão Salesiana de Mato Grosso. Como objetivos específicos pretende-se: a) estudar os modelos de curadoria digital disponíveis na literatura; b) investigar as práticas de curadoria digital em museus, bibliotecas e arquivos nacionais e internacionais; c) conhecer as políticas institucionais e documentos norteadores já estabelecidos nas unidades de informação da Missão Salesiana de Mato Grosso; d) elaborar um modelo integrador a partir da sistematização dos elementos informacionais das unidades; e) adaptar o modelo de curadoria digital a partir dos já existentes na literatura para os objetos digitais das unidades de informação estudadas; f) aplicar o modelo e verificar os resultados.

\subsection{Tema e Problema}

O tema deste estudo se refere ao uso da curadoria para gestão dos objetos digitais com o objetivo de garantir a sua preservação e acesso, uso e reuso ao longo do seu ciclo de vida. O foco está voltado para manter a informação digital acessível, interpretável e autêntica, garantindo este acesso por um longo período, independentemente da plataforma tecnológica utilizada, integrando objetos digitais das unidades de informação estudadas.

Essas unidades de informação armazenam documentos das etnias Xavante e Bororo que estão em diversos formatos e espalhados em diferentes repositórios, configurando um panorama que não permite, por exemplo, que um pesquisador realize a busca a esses documentos de forma integrada, impedindo uma utilização mais eficiente dos recursos disponibilizados pelos sistemas utilizados atualmente, 
além de trazer respostas mais relevantes e precisas às pesquisas realizadas pelos usuários, comprometendo o objetivo final dessas unidades de informação que consiste em disponibilizar a informação para seus usuários.

Não há ainda uma mensuração dos documentos que estão dispersos nessas unidades de informação. Objetos digitais já disponibilizados pelo Museu, por exemplo, possuem problemas na recuperação da informação pelo fato de estarem disponibilizados no site, mas não em uma base de dados, respeitando métodos de organização e classificação, com a devida indexação que permita a recuperação desses documentos por meio de descritores.

Nessa perspectiva, a curadoria digital surge como uma forma de garantir o acesso e a preservação dos objetos digitais das etnias Xavante e Bororo, com a finalidade de promover a busca integrada dos documentos dessas comunidades indígenas. Dessa forma, esta pesquisa busca estabelecer uma condição favorável para que o problema de pesquisa que é compreender de que forma a curadoria digital pode ser aplicada integrando unidades de informação possa ser respondido.

Houve investigação prévia nessas unidades de informação, constatando-se que existe um esforço por parte delas em reunir e disponibilizar os documentos e objetos que representam as etnias Xavante e Bororo. Este esforço converge com os anseios dessas comunidades que lutam para manter seus traços culturais ao longo de sua existência, traços esses que são mantidos por meio do registro da cultura, das crenças e valores, dos mitos e ritos, das músicas, das histórias, das práticas sociais, das artes e religiosidade desses grupos, que foram registradas por missionários que atuaram nessas comunidades, por pesquisadores que estudam essas etnias e pelos próprios membros dessas comunidades. Promover e garantir este acesso significa respeitar e valorizar a cultura indígena e os conhecimentos produzidos pelas etnias Xavante e Bororo.

A realização desta pesquisa é possível e viável, tendo em vista que se tem acesso ao conhecimento teórico e prático necessário para compor o estudo em nível nacional e internacional. Existem modelos conceituais que direcionam este processo para que as instituições possam dar conta de realizar a curadoria digital. No entanto, se constitui em um desafio contemplar a gestão dos objetos digitais das unidades de informação estudadas no modelo de curadoria, se caracteriza em uma tarefa complexa que exige o estudo aprofundado dessas unidades para conhecer a 
estrutura, processos, políticas, tecnologias e outros aspectos relevantes para se ter o entendimento necessário que se refletirá na estrutura do modelo integrador, garantindo a adaptação da curadoria digital para três ambientes diferentes.

Existe expressivo interesse na realização deste projeto por parte de todos os atores envolvidos, tendo em vista que as partes têm o real e similar entendimento sobre a importância da preservação e do acesso a documentos que possuem um significado especial para a cultura da região estudada, bem como para todo o Brasil, como é o caso das comunidades indígenas estudadas.

\subsection{Justificativa}

A justificativa deste estudo está, sobretudo, na importância que as ações de preservação digital apresentam diante da fragilidade da informação digital em decorrência da obsolescência tecnológica, o que torna a preservação em longo prazo e o acesso para as futuras gerações um desafio a ser enfrentado pelos profissionais da informação. Assim, estabelecer novas formas de trabalho, novas práticas que envolvam a gestão, o tratamento e a representação dos objetos digitais pode ser crucial para se obter êxito no objetivo final de uma unidade de informação que é disponibilizar a informação, afinal se uma unidade de informação é responsável por obter informação para disponibilizá-la, também é responsável por sua preservação, garantindo acesso permanente a ela.

A curadoria digital aparece, neste contexto, como uma forma de gerenciamento do objeto digital, incluindo atividades que compreendem todo o ciclo de vida dos objetos digitais, com a garantia de acesso futuro, sendo o monitoramento e a preservação etapas deste ciclo.

Destaca-se que, o uso de uma plataforma como potencializador do acesso à informação das três unidades de informação, de forma integrada, otimizando o acesso à informação pelo usuário, impacta diretamente na recuperação da informação que é o objetivo final de museus, bibliotecas e arquivos. Para a Biblioteca esta inciativa pode significar a inovação nos serviços de biblioteca, com o uso de dispositivos de informação (plataformas, websites, interfaces mais amigáveis) como forma de ampliação e remodelagem dos serviços, a partir da interação com o usuário na esfera do espaço virtual, na disponibilização desses objetos. Para o museu, o processo de curadoria digital aparece como garantia não só de acesso ao 
objeto digital museológico, mas como garantia de acesso à memória da cultura de um país, região, comunidade. No caso dos documentos arquivísticos, além de a preservação digital estar relacionada com os princípios arquivísticos, principalmente de integridade e autenticidade dos documentos, ressalta-se a visão de Sayão (2005) quando menciona que a curadoria vai além da preservação digital, pois visa preservar o conteúdo intelectual dos documentos, garantindo o acesso contínuo a este conteúdo.

Ao se ressaltar a importância do compartilhamento de informação entre as unidades estudadas, compreende-se que podem ser revelados valores importantes ocultos nos objetos digitais, que o olhar da gestão para a curadoria pode proporcionar, considerando a preservação, armazenamento e estruturação de apresentação dos objetos digitais.

Esta iniciativa visa aumentar a conscientização sobre os desafios estratégicos, culturais e tecnológicos que as unidades de informação enfrentam. Pode reforçar a importância de os museus, as bibliotecas e os arquivos criarem comissões para a tomada de decisão em relação aos planos de trabalhos e execução do projeto de curadoria, promovendo a integração entre os profissionais das três unidades de informação e entre os profissionais da área de sistemas, também envolvida neste processo.

Para Beagrie (2004) o gerenciamento e a preservação de materiais digitais são cada vez mais importantes para uma ampla gama de atividades dentro da educação e da pesquisa. Grande parte da base de conhecimento e ativos intelectuais de instituições e funcionários estão agora em formato digital. A menos que sejam empenhados esforços significativos em prol da preservação digital, garantindo acesso de longo prazo a esses recursos digitais, as incertezas sobre o arquivamento continuarão a impedir o crescimento e a adoção de serviços digitais e novas práticas de trabalho. Além disso, a menos que os ativos digitais possam ser preservados ao longo do tempo, o investimento atual em digitalização e conteúdo digital só garantirá benefícios de curto prazo, e não duradouros.

\section{REVISÃO DE LITERATURA}

O conceito de curadoria digital já vem sendo trabalhado em países como Estados Unidos e Reino Unido desde a década de 90. Como primeira inciativa, em 
1996, destaca-se o Relatório sobre o Arquivamento de Informações Digitais (em inglês: Task Force on Archiving of Digital Information) que retratava a necessidade do desenvolvimento de estratégias para garantir a preservação de informações digitais valiosas, destacando o importante papel das organizações (incluindo primeiramente as bibliotecas digitais) em realizar atividades voltadas para o gerenciamento e preservação de documentos digitais, incluindo a aplicação de estratégias para garantir a preservação e acesso (HIGGINS, 2011).

No Reino Unido, um workshop sobre preservação digital promovido pela Universidade de Warwick, em 1995 (mencionado no relatório Task Force), explorou uma série de questões estratégicas relacionadas à preservação digital, incluindo métodos, políticas e práticas. Antigamente, a preservação implicava em garantir que apenas alguns usuários tivessem autorização para acessar, com vistas a manter a integridade e autenticidade do documento. Ao longo dos últimos anos, o foco mudou para que haja garantia de que o material digital seja gerenciado ao longo do seu ciclo de vida, para que permaneça acessível a quem precisar usá-lo (HIGGINS, 2011).

O conceito de curadoria digital está associado à criação do Digital Curation Centre (DCC). Fundado em 2004, é um centro de especialização internacionalmente reconhecido em curadoria digital, com foco na capacidade de construção e habilidades para pesquisa de gerenciamento de dados (DIGITAL CURATION CENTRE, 2017).

Para o DCC, o objetivo de um programa de Curadoria Digital é salvaguardar os objetos digitais, possibilitando o acesso e o reuso em todo seu ciclo de vida. O retorno do investimento da curadoria vem do compartilhamento dos dados, evitando a repetição de esforços na criação destes, tornando-os disponíveis para extração de novos conhecimentos. Dessa forma, a curadoria digital permite: a) manter o documento íntegro e acessível, enquanto este possuir valor jurídico (evidência); b) extrair novos conhecimentos (valor informacional e de pesquisa); c) preservar a memória da sociedade (valor histórico); e d) evitar o retrabalho de recriar os dados já produzidos anteriormente (DIGITAL CURATION CENTRE, 2017).

No Brasil, os debates e iniciativas sobre Curadoria são mais recentes, como o exemplo da parceria entre o IBICT e a Stanford University para a implementação de serviços de preservação digital, em 2013, com a criação da Rede Brasileira de Serviços de Preservação Digital (Cariniana). O objetivo principal desta rede é 
disponibilizar serviços de preservação digital de recursos exclusivamente eletrônicos para a comunidade que lida com informação científica e tecnológica, passando também, a preservar digitalmente acervos patrimoniais de bibliotecas, arquivos e centros de memória institucionais no Brasil, garantindo o acesso continuado em longo prazo dos conteúdos científicos armazenados digitalmente (INSTITUTO BRASILEIRO DE INFORMAÇÃO EM CIÊNCIA E TECNOLOGIA, 2017).

Além da proximidade com a preservação digital, a curadoria digital é um conceito relacionado à curadoria de dados (também denominada eScience) e ainda está em pleno desenvolvimento, sendo utilizado primeiramente pelas comunidades científicas, dentro de bibliotecas eletrônicas ou digitais, com aplicações em repositórios institucionais, com o objetivo de garantir a preservação e acessibilidade aos dados de pesquisas científicas em longo prazo, mantendo-os disponíveis para uso e reuso (SANTOS, 2014).

Especificamente,

a curadoria digital é definida com a seleção, preservação, manutenção, coleção e arquivamento de ativos digitais [...]". "A preservação e acesso a recursos de informação digital é considerada a espinha dorsal da curadoria digital; são geralmente serviços invisíveis, executados dentro das unidades de informação. (SANTOS, 2014, p. 106).

A gestão ativa dos dados da pesquisa reduz as ameaças ao seu valor de pesquisa de longo prazo e mitiga o risco de obsolescência digital. (DIGITAL CURATION CENTRE, 2017).

Existem alguns modelos para o gerenciamento do ciclo de vida de objetos digitais, que em sua maioria, enfatizam a importância de considerar as melhores práticas para o arquivamento em todas as etapas do ciclo de vida da gestão da informação. Reconhecendo esta importante filosofia, Hodge (2000) reuniu as melhores práticas identificadas em um estudo, que se apresentam sob a seguinte estrutura: criação, aquisição, catalogação, identificação, armazenamento, preservação e acesso.

O modelo do ciclo de vida da curadoria digital desenhado pelo DCC compreende basicamente: a) Conceitualização: conceber e planejar a criação de objetos digitais, incluindo métodos de captura de dados e opções de armazenamento; b) Criação e/ou recebimento: produzir objetos digitais e atribuir metadados arquivísticos administrativos, descritivos, estruturais e técnicos; c) 
Acesso e uso: assegurar que os usuários designados possam acessar facilmente objetos digitais no dia-a-dia. Alguns objetos digitais podem estar disponíveis publicamente, enquanto outros podem ser protegidos por senha; d) Avaliação e seleção: avaliar objetos digitais e selecionar aqueles que precisam de curadoria e preservação a longo prazo. Aderir à orientação documentada, políticas e requisitos legais; e) Eliminação: eliminar sistemas de objetos digitais não selecionados para preservação de longo prazo. Para a eliminação segura dos objetos digitais, opte pela orientação documentada, políticas e requisitos legais; f) Migração: transferir objetos digitais para um arquivo, repositório digital confiável, data center ou similar, aderindo novamente a orientações documentadas, políticas e requisitos legais; g) Ações de preservação: realizar ações para assegurar a preservação e retenção em longo prazo da natureza autorizada dos objetos digitais; h) Reavaliação: retornar objetos digitais que falham nos procedimentos de validação para avaliação e possível seleção para curadoria; i) Armazenamento: manter os dados de forma segura, conforme descrito em padrões relevantes; j) Acesso, uso e reuso: assegure-se de que os dados sejam acessíveis aos usuários designados para uso e reutilização pela primeira vez. Alguns materiais podem estar disponíveis publicamente, enquanto outros dados podem ser protegidos por senha; e, k) Transformação: criar novos objetos digitais do original, como por exemplo, pela migração de diferentes formatos. (SAYÃO; SALES, 2012; DIGITAL CURATION CENTRE, 2017).

Higgins (2008) coloca que este modelo é de natureza genérica, sendo assim, ele é um modelo indicativo e não exaustivo, o que configura que nem toda instituição precisa cumprir todos os estágios do ciclo, mas sim adequá-lo às suas necessidades e realidade.

Além do próprio arquivamento e preservação de conteúdos e dados, existe uma preocupação com o arquivamento de links em documentos, tendo em vista que cada vez mais se pratica o uso extensivo de links de hipertexto para outros objetos digitais nas publicações eletrônicas, o que levanta a questão de saber se esses links e seu conteúdo devem ser arquivados junto com o item de origem. Segundo Hodge (2000), a maioria das organizações arquiva os links (URLs ou outros identificadores), mas não o conteúdo dos objetos vinculados. O que vai determinar se as instituições arquivem os conteúdos de links constantes em documentos por ela armazenados serão as diretrizes de seleção para inclusão de conteúdos vinculados a documentos originais. O autor destaca dois projetos que arquivam o conteúdo de todos os links: o 
Internet Archive e a American Astronomical Society, trabalhando de forma colaborativa com outras associações, sociedades, pesquisadores, universidades e agências governamentais, no qual cada organização arquiva suas próprias publicações, mas os links são mantidos não só nas referências dos artigos, mas também nas principais bases de dados da área. Dessa forma, todos os conteúdos dos objetos digitais vinculados estão disponíveis.

\section{PROCEDIMENTOS METODOLÓGICOS}

Os procedimentos metodológicos da pesquisa envolvem a pesquisa bibliográfica, exploratória, pesquisa documental, com abordagem qualitativa e elementos de estudo de caso.

A pesquisa bibliográfica consiste na etapa inicial de todo trabalho científico, pois visa reunir informações acerca de determinado assunto. É realizada com base em material publicado em livros, jornais, revistas, sites na Internet, e que sejam disponibilizados ao público em geral (VERGARA, 2007). Não fugindo à regra, neste estudo a pesquisa bibliográfica estará presente em dois momentos cruciais do trabalho: na revisão de literatura e na composição do modelo a ser entregue como resultado do estudo.

A abordagem da pesquisa é predominantemente qualitativa, e considerada por Richardson (1999) como uma forma adequada para entender à natureza de um fenômeno social. No caso deste estudo, o caráter qualitativo se reflete no entendimento da rotina de trabalho das unidades de informação e de seus profissionais, por meio da pesquisa documental e das entrevistas que serão realizadas, com o intuito de entender como acontece o acesso ao acervo/coleção e seu uso pelo público, e no entendimento sobre as crenças e valores da Instituição mantenedora, para poder traçar um plano de trabalho que respeite e atenda às demandas da Instituição.

Os estudos exploratórios permitem ao investigador aumentar sua experiência em torno de um determinado problema, partem de uma hipótese e aprofundam seu estudo aos limites de uma realidade específica, buscando antecedentes, maior conhecimento para, em seguida, planejar uma pesquisa (TRIVIÑOS, 1987). O caráter exploratório permitirá ampliar a visão que se possui em relação à problemática abordada, podendo confirmar ou refutar as hipóteses delimitadas para 
a pesquisa.

Esta pesquisa consiste em um estudo de caso aplicado à Missão Salesiana de Mato Grosso, tendo em vista que vai envolver "o estudo profundo e exaustivo de um ou poucos objetos de maneira que se permita o seu amplo e detalhado conhecimento" (SILVA; MENEZES, 2005, p. 21), com a investigação dos fenômenos relativos aos procedimentos de trabalho da população pesquisada.

$\mathrm{Na}$ implementação do modelo de curadoria digital, a base será composta por meio dos estudos dos modelos levantados, congregando boas práticas de curadoria digital, advindas da Digital Preservation Coalition, por exemplo, com a utilização de um Ambiente de Gestão de Documentos (SIGAD), uma plataforma, o Repositório Arquivístico Digital Confiável (Archivematica) e a Plataforma de Descrição, Difusão e Acesso (AtoM ou ICA-AtoM), constituindo, assim, o Ambiente de Preservação e Acesso. (GUIA DO USUÁRIO ARCHIVEMATICA, 2016). Todas estas ferramentas são livres e de código aberto, permitindo sua utilização sem custos de aquisição.

Além dos softwares mencionados, para promover o acesso aos diferentes objetos digitais será necessário desenvolver um sistema com linguagem de marcação XML e HTML. Com a tecnologia HTML será possível a criação de uma interface que propiciará a manipulação dos dados em XML. Para a captura dos diversos documentos digitais das diferentes unidades de informação será utilizado um banco de dados web, que promoverá o acesso aos documentos digitais das etnias Xavante e Bororo, a serem disponibilizadas ao público usuário.

O modelo de curadoria será considerado no desenho deste ambiente, de forma a atender e contemplar as especificidades de cada unidade de informação, no que diz respeito principalmente à organização e representação da informação, neste caso os objetos digitais. Para que esta ideia se torne possível, um extenso trabalho de pesquisa será realizado buscando compreender no âmbito de cada UI: a) como são realizados os processos de catalogação, classificação e indexação; b) como são selecionados os metadados e sua utilização em cada processo/sistema; c) quais as políticas, diretrizes, documentos norteadores são utilizados (segurança, armazenamento, aquisição, desenvolvimento de coleções, boas práticas, qualidade, infraestrutura tecnológica, arquivamento, publicação, licenças, capacitação etc.); d) quais sistemas são utilizados (acesso, tipos de dados, interoperabilidade, formatos, curadoria, serviços, metadados, documentação etc.).

Para que se possa fazer a gestão dos dados ativos por meio da curadoria 
digital, será elaborado um modelo que visa consolidar/promover a integração dos diversos elementos informacionais que envolvem as três unidades de informação. A pesquisa, portanto, se constitui de uma parte prática, cuja implementação das ferramentas descritas acima, faz parte integrante do projeto, para adequação ao modelo de curadoria escolhido para o estudo, tendo sua aplicação voltada para a Missão Salesiana de Mato Grosso, ou seja, a curadoria digital será a forma virtual de organizar e disponibilizar aos acervos e coleções.

Como instrumentos de coleta de dados pensou-se inicialmente em entrevistas, tendo em vista que a obtenção de informações será necessária e obtida por meio da participação das equipes das três unidades de informação e a observação sistemática, pois se considera que para a realização da pesquisa será necessário um planejamento, em condições controladas para responder aos propósitos preestabelecidos (SILVA; MENEZES, 2005). Estas informações configurarão em um diagnóstico utilizado para compor o modelo integrador.

Num primeiro momento, as etapas macro da tese estão estruturadas conforme especificado no Quadro 1.

Quadro 5 - Cronograma preliminar da tese

\begin{tabular}{|l|c|c|c|c|c|c|c|c|}
\hline Atividades & $\mathbf{2 0 1 8}$ & $\mathbf{2 0 1 8}$ & $\mathbf{2 0 1 9}$ & $\mathbf{2 0 1 9}$ & $\mathbf{2 0 2 0}$ & $\mathbf{2 0 2 0}$ & $\mathbf{2 0 2 1}$ & $\mathbf{2 0 2 1}$ \\
\hline $\begin{array}{l}\text { Estudos iniciais sobre curadoria digital } \\
\text { e demais temas relacionados à tese }\end{array}$ & $\mathrm{x}$ & $\mathrm{x}$ & & & & & & $\mathbf{2}$ \\
\hline $\begin{array}{l}\text { Ajuste do problema/hipóteses/questões } \\
\text { de pesquisa }\end{array}$ & & & $\mathrm{x}$ & & & & & \\
\hline Levantamento do referencial teórico & $\mathrm{x}$ & $\mathrm{x}$ & & & & & & \\
\hline $\begin{array}{l}\text { Elaboração do referencial } \\
\text { teórico/estado da arte/enquadramento } \\
\text { teórico }\end{array}$ & & $\mathrm{x}$ & $\mathrm{x}$ & $\mathrm{x}$ & $\mathrm{x}$ & $\mathrm{x}$ & & \\
\hline $\begin{array}{l}\text { Definição/ajuste dos procedimentos } \\
\text { metodológicos }\end{array}$ & & $\mathrm{x}$ & $\mathrm{x}$ & & & & & \\
\hline Qualificação & & & & $\mathrm{x}$ & & & & \\
\hline $\begin{array}{l}\text { Levantamento/coleta dos } \\
\text { dados/elaboração do } \\
\text { diagnóstico/entrevistas/questionário/ob } \\
\text { servação }\end{array}$ & & & & & & & & \\
\hline Tratamento dos dados coletados & & & & & & $\mathrm{x}$ & & \\
\hline $\begin{array}{l}\text { Elaboração do modelo } \\
\text { integrador/concepção da plataforma e } \\
\text { interface }\end{array}$ & & & & & & $\mathrm{x}$ & & \\
\hline $\begin{array}{l}\text { Aplicação das etapas de curadoria } \\
\text { digital }\end{array}$ & & & & & & $\mathrm{x}$ & $\mathrm{x}$ & \\
\hline Testes finais & & & & & & & & $\mathrm{x}$ \\
\hline $\begin{array}{l}\text { Análise dos resultados e } \\
\text { discussão/conclusões }\end{array}$ & & & & & & & & $\mathrm{x}$ \\
\hline Revisão da Redação & & & & & & & $\mathrm{x}$ \\
\hline Defesa & & & & & & $\mathrm{x}$ & \\
\hline
\end{tabular}


Fonte: Elaborado pela autora (2018).

\section{CONSIDERAÇÕES PARCIAIS}

A iniciativa desta pesquisa partiu da observação do cotidiano, da prática profissional, na qual se percebe que os diferentes tipos de unidades de informação carecem de políticas formalizadas, sobretudo no que diz respeito à preservação digital, conforme pode-se confirmar no resultado da pesquisa de Baggio (2016). Isso pode acontecer por diversos motivos que vão desde à escassez de recursos de natureza diversa, como por exemplo, o reduzido quadro de funcionários, até o desconhecimento sobre este assunto, que pode ser considerado relativamente novo.

Além de se consolidar em um problema real, este projeto reflete a crescente necessidade de se conhecer a realidade das unidades de informação frente à utilização de novas tecnologias. Destaca-se especialmente a necessidade de se conhecer, desenhar e aplicar a curadoria digital como uma forma de gerenciar os objetos digitais dessas unidades de informação, mais especificamente do ponto de vista da guarda e preservação documental e da garantia de acesso futuro a esses documentos, uso e reuso por meio de uma plataforma que integre os objetos digitais das unidades de informação a serem estudadas neste projeto.

Unidades de informação são designadas para cumprir as funções de encontrar, selecionar e disseminar a informação ao seu público específico, garantindo que tenham acesso simples e efetivo aos recursos de informação. A aplicação de tecnologia, modifica as características das unidades de informação, facilitando o acesso e agregando valor às atividades realizadas nessas unidades. Decorrente do uso de tecnologia nas unidades de informação, destaca-se a ênfase no desenvolvimento de medidas e padrões por meio de um planejamento, buscando garantir o sucesso das atividades. Assim, esta proposta poderá permitir que o uso do acervo seja tangível, visível e mensurável, tendo em vista a facilidade de acesso às coleções digitais.

Entende-se que museus, bibliotecas e arquivos tem nas suas atividades um propósito maior que significa atender o seu público usuário, objetivando a educação, pesquisa e geração de conhecimento. Com as tecnologias de informação, esta função se transporta para o acesso e uso dos acervos das unidades de informação 
como forma de ampliação do conhecimento dos usuários.

Dessa forma, como resultado esperado, pretende-se apresentar e implementar um modelo integrador dos objetos digitais das unidades de informação estudadas, apoiada na curadoria digital, permitindo disponibilizar as coleções/acervos virtualmente a toda a comunidade de usuários.

\section{REFERÊNCIAS}

BAGGIO, C. C. Análise das políticas de informação dos repositórios institucionais das Universidades Federais do Brasil. 2016. 352 p. Dissertação (Mestrado) - Universidade Federal de Santa Catarina, Centro de Ciências da Educação, Programa de Pós-Graduação em Ciência da Informação, Florianópolis, 2016. Disponível em: <http://tede.ufsc.br/teses/PCIN0141-D.pdf>. Acesso em: 10 maio 2018.

BEAGRIE, N. Digital curation for science, digital libraries, and individuals. International Journal of Digital Curation, v. 1, p. 3-15, nov. 2006. Disponível em: <http://www.ijdc.net/index.php/ijdc/article/view/6/2>. Acesso em: 25 ago. 2017.

The continuing access and digital preservation strategy for the UK Joint Information Systems Committee (JISC). D-Lib Magazine, v. 10, n. 7/8, jul./aug. 2004. Disponível em: <http://www.dlib.org/dlib/july04/beagrie/07beagrie.html>. Acesso em: 28 ago. 2017.

CONSELHO NACIONAL DE ARQUIVOS (Brasil). Câmara Técnica de Documentos Eletrônicos. e-ARQ Brasil: Modelo de Requisitos para Sistemas Informatizados de Gestão Arquivística de Documentos: 1.1 versão. Rio de Janeiro: Arquivo Nacional, 2011.

DIGITAL CURATION CENTRE. What is digital curation? Disponível em: <http://www.dcc.ac.uk/digital-curation/what-digital-curation>. Acesso em: 21 jul. 2017.

FERREIRA, M. Introdução à preservação digital: conceitos, estratégias e actuais consensos. Guimarães, Portugal: Escola de Engenharia da Universidade do Minho, 2006. Disponível em:

<http://repositorium.sdum.uminho.pt/bitstream/1822/5820/1/livro.pdf>. Acesso em: 10 jul. 2017.

GRAY, Jim. eScience: a transformed scientific method. Palestra apresentada no Conselho Nacional de Pesquisa dos Estados Unidos (NRC-CSTB). Mountain View, Califórnia, 11 jan. 2007. Disponível em:

$<$ http://languagelog.Idc.upenn.edu/myl/JimGrayOnE-Science.pdf>. Acesso em: 30 ago. 2017.

GUIA DO USUÁRIO ARCHIVEMATICA. Brasília: Instituto Brasileiro de Informação em Ciência e Tecnologia, 2016. 
HIGGINS, S. Digital curation: the emergence of a new discipline. International Journal of Digital Curation, Penglais, v. 6, n. 2, p.78-88, jun. 2008. Disponível em: <http://ijdc.net/index.php/ijdc/article/view/184>. Acesso em: 10 jul. 2017.

The DCC curation lifecycle model. International Journal of Digital Curation, v. 3, n. 1, p.134-140, set. 2011. Disponível em: <http://www.ijdc.net/index.php/ijdc/article/view/69>. Acesso em: 10 jul. 2017.

HODGE, G. M. Best practices for digital archiving: an information life cycle approach. D-Lib Magazine, v. 6, n. 1, jan. 2000. Disponível em: <http://www.dlib.org/dlib/january00/01hodge.html>. Acesso em: 25 ago. 2017.

ICA-ATOM (Open source archival description software). About the software. 2017. Disponível em: <https://www.ica-atom.org/>. Acesso em: 24 jul. 2017.

INSTITUTO BRASILEIRO DE INFORMAÇÃO EM CIÊNCIA E TECNOLOGIA (IBICT). Rede Cariniana. Disponível em: <http://cariniana.ibict.br/>. Acesso em 20 jul. 2017.

MISSÃO SALESIANA DE MATO GROSSO (MSMT). História. 2018. Disponível em: <http://www.missaosalesiana.org.br/historia/>. Acesso em: 02 maio 2018.

RICHARDSON, R. J. Pesquisa social: métodos e técnicas. 3. ed. São Paulo Atlas: 1999.

SANTOS, T. N. C. Curadoria digital: o conceito no período de 2000 a 2013. 2014. 165f. Dissertação (Mestrado) - Programa de Pós-Graduação em Ciência da Informação, Faculdade de Ciência da Informação, Universidade de Brasília, Brasília, DF, 2014.

SAYÃO, L. F. Preservação digital no contexto das bibliotecas digitais: uma breve introdução. In: MARCONDES, C. H. et al. (Org.). Bibliotecas digitais: saberes e práticas. Salvador: UFBA, 2005, p. 115-145.

SAYÃO, L. F.; SALES, L. F. Curadoria digital: um novo patamar para preservação de dados digitais de pesquisa. Inf. \& Soc.: Est., João Pessoa, v. 22, n. 3, p. 179-191, set./dez. 2012. Disponível em:

<http://basessibi.c3sl.ufpr.br/brapci/ repositorio/2015/12/pdf e65e207da9 00000119 52.pdf>. Acesso em: 10 jul. 2017.

SILVA, E. L. da; MENEZES, E. M. Metodologia da pesquisa e elaboração de dissertação. 4. ed. Florianópolis: UFSC, 2005.

TRIVIÑOS, A. N. S. Introdução à pesquisa em ciências sociais: a pesquisa qualitativa em educação. São Paulo: Atlas, 1987.

VERGARA, S. C. Projetos e relatórios de pesquisa em administração. 4. ed. São Paulo. Atlas, 2007. 